\title{
Identifying LCA-elements in scrap tire recycling
}

\author{
A. Pehlken ${ }^{1} \&$ G. Roy ${ }^{2}$ \\ ${ }^{1}$ Institute and Chair of Processing and Recycling of Solid Waste \\ Materials, RWTH Aachen University, Germany \\ ${ }^{2}$ Materials Technology Laboratory, Natural Resources Canada, Canada
}

\begin{abstract}
Scrap tire recycling is presented in this paper with LCA-elements identified for further investigation. Life cycle thinking is applied to the life cycle of scrap tires because not much data is available for the recycling of scrap tires. The scrap tires discussed in this paper are provided as raw material input, and the output is shown as different products, such as retreaded tires, crumb rubber, artificial turf energy recovery and many others. The environmental impacts are focussed on the climate change, in particular on $\mathrm{CO}_{2}$-emissions. The potential to reduce the emissions that support environment-friendly recycling techniques will also be presented. Thermodynamic fundamentals are introduced to set the path for the next phase of the study, where analytical and numerical models based on finite element method (FEM) computer calculations can be performed.

Keywords: LCA, Life cycle thinking, scrap tires, climate change, $\mathrm{CO}_{2}$-emissions, environment, thermodynamics
\end{abstract}

\section{Introduction}

Life cycle assessment (LCA) is a methodological framework for estimating and assessing the environmental impacts attributable to the life cycle of a product, such as climate change, eutrophication, acidification, depletion of resources, water use, and others. An LCA practitioner tabulates the emissions and the consumption of resources, as well as other environmental exchanges at a very relevant stage (phase) in a product's life cycle, from "cradle to grave", including raw material extractions, energy acquisition, material production, manufacturing, use, recycling and ultimate disposal. The processes within the life cycle and the 
associated material and energy flows as well as other exchanges are modelled to represent the product system and its total inputs and outputs from and to the natural environment, respectively. This results in a product system model and an inventory of environmental exchanges related to the functional unit [1].

An LCA can be applied to any kind of product and to any decision where the environmental impacts of the complete or part of the life cycle are of interest. In this paper the product scrap tire will be investigated and life cycle-elements will be identified.

\section{Scrap tires}

Tires that cannot be used for their intended purpose are considered as scrap tires. There are different processing routes for various kinds of tires depending on their size and composition.

The life span of a tire is about $80,000 \mathrm{~km}$ depending on the workload. There might be tires, which last for $100,000 \mathrm{~km}$ or just $40,000 \mathrm{~km}$. The life span depends on the proper tire pressure as well as on the driving behaviour and the road conditions.

\subsection{Composition}

The composition can vary from manufacturer to manufacturer. Therefore, the exact composition of a bulk of scrap tire is not always known, and hence it represents an uncertain number in the process. Most countries estimate an average composition for their scrap tires.

Table 1 shows the average composition of a European car tire with carbon black filler and silica filler and an American car tire. As can be seen, the American car tire tends to have more natural rubber content and it weighs more than $2 \mathrm{~kg}$ in comparison with the European tire.

Tires intend to loose approximately $15 \%$ of their weight during their lifetime, which is mainly rubber loss. The average scrap tire in North America weighs around $9 \mathrm{~kg}$ and in Europe around $7.5 \mathrm{~kg}$. Furthermore, only tires with carbon black filler and none with Silica filler are manufactured in North America. In Europe, both silica and carbon black fillers can be found in tires. The exact tire composition is not known because of company secrets. Therefore, the numbers represent an average of the tire composition.

\subsection{Scrap tire processing per country}

The various possibilities of tire disposition differ from country to country. Most countries are banning or supporting special technologies. In Europe, for example, it is no longer allowed to landfill unprocessed tires (landfill directive 199/31/EC) since the beginning of 2003. The USA and Canada tend to have different legislations in each state or province, respectively. The average dispositions of scrap tires in the USA and Canada and the EU with 15 member countries are listed in Table 2. 
Table 1: $\quad$ Car tire composition [2,3].

\begin{tabular}{|c|c|c|c|}
\hline Raw Material & $\begin{array}{l}\text { European Car Tire } \\
\text { (carbon black) }\end{array}$ & $\begin{array}{l}\text { European Car Tire } \\
\text { (silica) }\end{array}$ & $\begin{array}{l}\text { American Car } \\
\text { Tire }\end{array}$ \\
\hline & Amount in wt $\%$ & Amount in wt $\%$ & Amount in wt $\%$ \\
\hline Synthetic Rubber & 24.83 & 24.17 & 14.00 \\
\hline Natural Rubber & 16.91 & 18.21 & 27.00 \\
\hline Carbon Black & 26.91 & 19.00 & 28.00 \\
\hline Synthetic Silica & 0.57 & 9.65 & \\
\hline Sulphur & 1.35 & 1.28 & \multirow{7}{*}{ 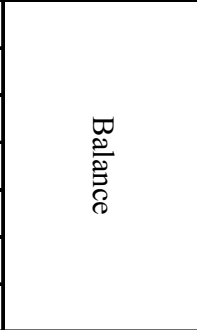 } \\
\hline $\mathrm{ZnO}$ & 1.55 & 1.58 & \\
\hline Aromatic Oils & 7.81 & 6.12 & \\
\hline Stearic Acid & 0.79 & 0.96 & \\
\hline Accelerators & 0.88 & 1.01 & \\
\hline Antidegradants & 1.51 & 1.47 & \\
\hline Recycled Rubber & 0.41 & 0.50 & \\
\hline Coated Wires & 11.70 & 11.40 & 15.00 \\
\hline Textile Fabric & 4.70 & 4.70 & 5.00 \\
\hline Weight (kg) & 8.62 & 8.80 & 11.00 \\
\hline
\end{tabular}

Table 2: $\quad$ Disposition of scrap tires in countries $[4,5,6]$.

\begin{tabular}{|l|r|r|r|}
\hline \multirow{2}{*}{$\begin{array}{c}\text { Disposition of scrap tires } \\
\text { 2003/2004 }\end{array}$} & \multicolumn{1}{c|}{ USA } & \multicolumn{1}{c|}{ Canada } & \multicolumn{2}{c|}{ Europe (EU15) } \\
\cline { 2 - 4 } & Amount in wt $\%$ & Amount in wt $\%$ & Amount in wt\% \\
\hline Tire Derived Fuel & 44.7 & 20.0 & 30.0 \\
\hline Civil Engineering & 19.4 & 13.0 & incl. in Ground Rubber \\
\hline Unknown & 10.3 & 0.0 & - \\
\hline Ground Rubber / products & 9.7 & 62.0 & 28.0 \\
\hline Landfill & 9.3 & 0.0 & 18.0 \\
\hline Export & 3.1 & 0.0 & 6.0 \\
\hline Punched / Stamped & 2.0 & incl. in Civil Engin. & 0.0 \\
\hline Electric Arc Furnaces & 0.2 & 0.0 & 0.0 \\
\hline Retreading & only truck tires & only truck tires & 12.0 \\
\hline Misc./Agriculture & 1.7 & 5.0 & 6.0 \\
\hline
\end{tabular}

As can be seen in the table, the USA is processing nearly half of their scrap tires into Tire Derived Fuel, whereas Europe is retreading up to $15 \%$ of the passenger and truck tires. The number for Landfill in Europe is changing dramatically because of legislation that bans land filling of scrap tires from 2006. 
Canada puts much effort into ground rubber and products, which represents $62 \%$ of the processed scrap tires.

\section{LCA in Scrap tire processing}

Scrap tire processing can be very complex or very simple, depending on the goal. Scrap tires can be retreaded and further used as a tire. But this is limited and not every tire can be retreaded. In order to meet safety requirements, only carefully inspected tire bodies are retreaded. Most scrap tires are used to make other products, or they are used as energy recovery as tire derived fuel (TDF). In the USA nearly the half of all scrap tires are used as TDF, mostly in cement kilns or power plants. Canada is supporting the manufacture of new products from (recycled) rubber obtained by the scrap tire processing. All different technologies implement various input and output. For each process all required energy and additional materials have to be identified.

The life cycle of a scrap tire can be seen in Figure 1.

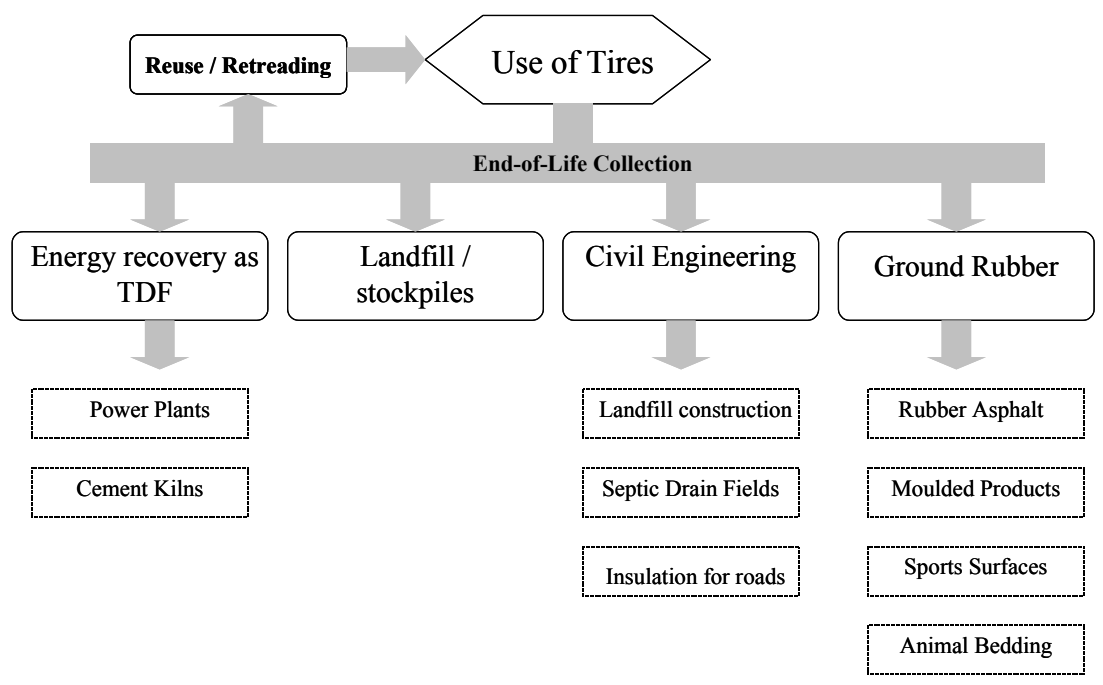

Figure 1: Life cycle of a scrap tire.

The goal of the assessment can be seen, for example, as product improvement or establishment of the average environmental profile. The average scrap tire composition can be taken as a basis for the calculation or if the recycling plant knows exactly their scrap tire composition this basis is recommended for further investigation. The assessment describes how the environmental exchanges of the system can be expected to change as a result of action taken in the system.

An example of the system boundaries for scrap tire processing is shown in Figure 2. Only the parameters that influence the $\mathrm{CO}_{2}$-Emissions are taken into account, and they have an impact on the climate change. The impact on 
eutrophication, acidification, depletion of resources, water use, etc. is not presented in detail in this figure. With any changes within the system boundaries, for example implementing a second or third sorting step, it may have an influence on the input (more energy required) and the output (more air emissions). The induced demand for one unit of product leads to the production and supply of one unit of products with associated emissions and resource consumptions [1].

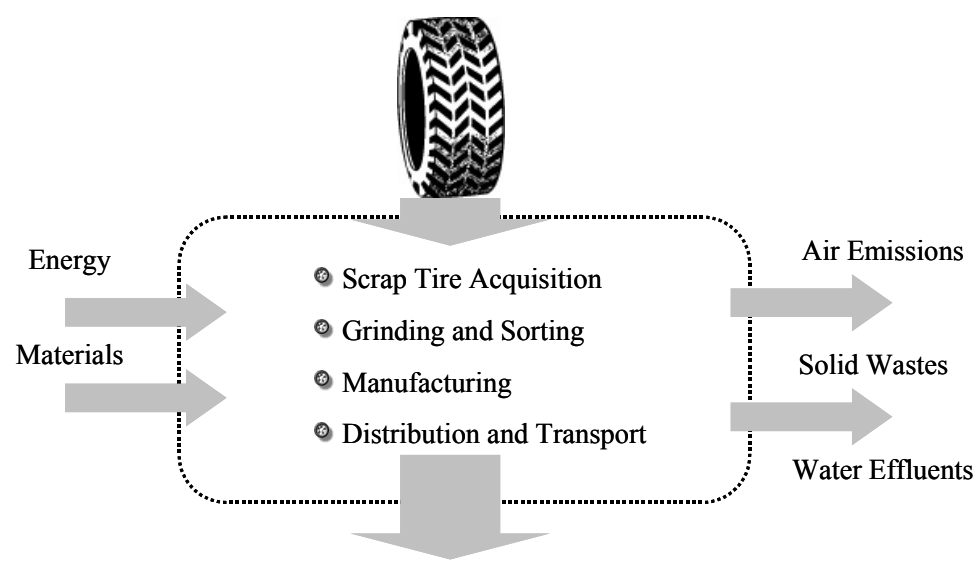

Output as Products or Energy

Figure 2: $\quad$ System boundaries for scrap tire processing.

Very important in regarding the life cycle of a scrap tire is the issue that it (the scrap tire) cannot be separated from the life cycle of a new tire. If anything changes in the composition of a new tire, it will have an influence on the composition of the scrap tire a few years later as well. Therefore, the processors have to overview the tire market as well and make adjustments to their process as needed. The life cycle assessment can help to identify the needed corrections.

\section{Life cycle thinking}

Often a detailed LCA is not applicable. Because of the lack of data or time simplified LCAs and LCA thinking has to be employed to provide efficient and reliable decision support in a relatively brief period of time. Rebitzer et al. [1] outlines the different methods in detail. There are different strategies for the simplification of the LCA, depending on goal and scope of the study, the required level of detail, the acceptable level of uncertainty, and the available resources. Especially in small companies, like most tire recyclers are, an LCA gives both environmental and economic benefits. They cannot risk it to make an incorrect decision because they might risk the future of the whole company. 


\subsection{Identified LCA-elements}

An LCA-element with major influence on the scrap tire processing is the scrap tire composition. The composition of the scrap tire is never known accurately, because of tire manufacturing companies' secrets and the various different tire models. The tire processor has to deal with the input, which is difficult to predict and can hardly be influenced by the processor. Therefore, an average basis has to be used for the assessment, and it remains uncertain. Table 1 has given the average composition of either European tires or American tires, which can represent the input.

Greenhouse gas (GHG) emissions are a big issue concerning climate change and must be recorded. Most GHG emissions are connected to the energy consumption or the replacement of other virgin materials. If carbon black $(100 \%$ Carbon) can be recovered from scrap tires through pyrolysis, there is a huge benefit for the GHG emissions, because less virgin carbon black has to be produced. National or international regulations influence the scrap tire process as well because some recycling techniques might be banned or not.

Manufacturing of new products has been identified as another important element within LCA of s scrap tire. Some products require more crushing steps than others, which means that more energy is needed. More energy results in higher greenhouse gas emissions. On the other hand there might be a benefit if other natural resources are replaced (using recycled rubber instead of generating new synthetic rubber).

\subsection{Greenhouse gas emissions}

The energy input into the recycling plant may be of major interest, depending on how the energy is generated. A power plant based on coal emits far more greenhouse gases than a power plant based on water or wind. Table 3 shows greenhouse gas emission factors for Canadian electricity in 2003 for all Canadian Provinces and Territories.

As can be seen, there are huge differences in greenhouse gas emissions. The province, Quebec, Manitoba and British Columbia have mostly hydroelectric power plants and therefore the emission factor for greenhouse gases is very low.

For the manufacturing of products it makes a difference what kind of energy is used within the process. Therefore, the location of a plant might be of interest because it is related to greenhouse gas emissions. A recycler in the province Alberta has double greenhouse gas emissions than a recycler in New Brunswick, or approximately 125 times higher greenhouse gas emissions than in the province of Quebec. This does not apply to plants, which are using own generated energy, like a pyrolysis or microwave plant.

Another issue is transportation, because it emits $\mathrm{CO}_{2}$ as well. For example for one litre of diesel approximately $2.7 \mathrm{~kg}$ of $\mathrm{CO}_{2}$ are emitted [8]. This has to be taken into account if scrap tires are transported for long distances. If the energy needed for the transport exceeds the energy recoverable from the scrap tires, the following processing is no longer environmentally beneficial. 
Furthermore the recycling technologies must not exceed the potential energy in a scrap tire. The Table 4 gives an overview of the needed energy with regards to (scrap) tires.

Table 3: $\quad$ Power Plant Emissions in Canada [7].

\begin{tabular}{|l|c|}
\hline \multicolumn{2}{|c|}{$\begin{array}{c}\text { Greenhouse Gas Emission Factors for Canadian Electricty in 2003 } \\
\text { (Factors Expressed in grams per kW-hour of end use) }\end{array}$} \\
\hline Province & Power Plant Emissions \\
\hline Newfoundland \& Labrador & 152 \\
\hline Prince Edward Island & 488 \\
\hline Nova Scotia & 642 \\
\hline New Brunswick & 468 \\
\hline Quebec & 8 \\
\hline Ontario & 309 \\
\hline Manitoba & 76 \\
\hline Saskatchewan & 860 \\
\hline Alberta & 1009 \\
\hline British Columbia & 24 \\
\hline Yukon & 38 \\
\hline North West Territories & 399 \\
\hline Nunavut & 269 \\
\hline CANADA in total & 269 \\
\hline
\end{tabular}

Table 4: $\quad$ Energy and (scrap) tires [9].

\begin{tabular}{|l|c|}
\cline { 2 - 2 } \multicolumn{1}{l|}{} & in $\mathrm{kWh} / \mathrm{kg}$ \\
\hline Energy needed to manufacture a tire & 32.0 \\
\hline Energy needed to produce tire rubber compound & 25.0 \\
\hline Thermal energy released when incinerating scrap tires & 9.0 \\
\hline $\begin{array}{l}\text { Energy consumed in the process of grinding scrap tires } \\
\text { into crumb rubber }(0.5 \text { to } 1.5 \mathrm{~mm})\end{array}$ & 1.2 \\
\hline
\end{tabular}

Tire manufacturing is an energy intensive process. Therefore, it might be worthwhile to recover the material form tires and take it back into the process. But there are quality issues to deal with, and manufacturing other rubber products from recycled rubber might be a solution as well. Compared to the energy needed to produce tire rubber compound, the energy consumed in the process of grinding scrap tires into crumb rubber is about 20 times less. The 
GHG emissions are directly related to the energy consumed by the processing and vary from location to location due to the source of energy supply.

\section{Thermodynamics of climate change}

To be able to model changes in climate caused by generation and/or influx of $\mathrm{CO}_{2}$, and to quantify the changes, a definition of a climatic system is introduced. It is understood that the amount of heat content in a certain volume of space, or climatic system, is the total energy content of the volume, known also as enthalpy $\mathrm{H}$, and equal to $\mathrm{U}+\mathrm{PV}$, where $\mathrm{U}$ is the internal energy of the system, provided by its vibrating molecules, $\mathrm{P}$ is the pressure exerted on the system by its environment, and $\mathrm{V}$ is the volume of the system. It should be obvious from the definition of the enthalpy, that if any changes inside the system occur unopposed by the external pressure, then the change in enthalpy is equal to the heat transferred during the process. Therefore, when the mass of the volume at a constant pressure gets converted into atoms, the enthalpy will change, and the new state of energy is called enthalpy of atomization. In our case, which is combustion and generation of $\mathrm{CO}_{2}$, the process is called enthalpy of combustion. The change in enthalpy, $\Delta \mathrm{H}$, will cause a change in another thermodynamic variable, entropy, or $\mathrm{S}$. Any small amounts of change of $\mathrm{S}$ are denoted $\Delta \mathrm{S}$ and they are equal to $\Delta \mathrm{Q} / \mathrm{T}$, where $\mathrm{T}$ is the temperature at which the change occurred. The change of entropy is a measure of disorder or randomness of an isolated system, which in our case means the volume of space occupied by the tires and the generated $\mathrm{CO}_{2}$.

For any testing equipment to measure changes in $\mathrm{CO}_{2}$, its sensitivity must be gauged against a known standard. For the current study, the standard is assumed to be a change in temperature, $\Delta \mathrm{T}_{\mathrm{n} \times \mathrm{CO} 2}$, caused by an $\mathrm{n}$-fold increase of the number of the molecule carbon dioxide, $\mathrm{CO}_{2}$. To perform such measurements, the number $\mathrm{n}$ must be selected before the measurements, and an attempt to calibrate the equipment must be stated.

To predict a global climate change, one can use a heat equation,

$$
\mathrm{c}_{\mathrm{P}} \mathrm{d} / \mathrm{dt}\left(\Delta \mathrm{T}_{\mathrm{n} \times \mathrm{CO} 2}\right)=\Delta \mathrm{Q}-\mu \Delta \mathrm{T}_{\mathrm{n} \times \mathrm{CO} 2}
$$

where $c_{\mathrm{P}}$ denotes the heat capacity of the system, tires and $\mathrm{CO}_{2}$, under constant pressure, and $\mu$ is the thermodynamic parameter, related to the entropy, and expressed as the ratio

$$
\Delta \mathrm{Q}_{\mathrm{n} \times \mathrm{CO} 2} / \Delta \mathrm{T}_{\mathrm{n} \times \mathrm{CO} 2}
$$

The heat capacity, $\mathrm{c}_{\mathrm{P}}$, and $\Delta \mathrm{Q}_{\mathrm{n} \times \mathrm{CO} 2}$ (to calculate the parameter $\mu$ ), can be estimated from a variety of measurements on the earth, and typical values for a 2-fold increase of carbon dioxide, i.e. when $\mathrm{n}=2$, are $1.1 \pm 0.5 \mathrm{GJ} / \mathrm{mK},[10-11]$ (Giga Joule per meter Kelvin) and $3.7 \mathrm{~W} / \mathrm{m}^{2}$ (Watt per square m), respectively. The climate sensitivity $\Delta \mathrm{T}_{\mathrm{n} \times \mathrm{CO} 2}$, can be determined from the above equations, if $\mu$ is well measured for tires. 


\section{Discussion}

The paper shows that there are possibilities for greenhouse gas reduction within scrap tire processing. Life cycle thinking can help to assess the potential. Scrap tires can provide energy in other processes and replace natural resources. They have a higher energy content than coal and can therefore be successful in saving greenhouse gases. But higher potential can be achieved through material recovery and replacing virgin synthetic rubber in other manufacturing processes. Further work is needed to get more reliable data on this issue.

The simple heat equation can be used to predict the change of entropy changes, and thus the amount of randomness if certain scrap tires are used to generate energy, by calculating the change in heat content. The higher energy content in tires than in coal can be quantified through analytical and numerical models based on finite element method (FEM) computer calculations.

\section{References}

[1] Rebitzer et al., Life cycle assessment, Part 1: Framework, goal and scope definition, inventory analysis, and applications, Environment International 30 (2004), pp701-720, 2004.

[2] BLIC-The European Car Tyre Manufacturers. Life Cycle Assessment of an Average European Car Tyre. Third party report May 2001. www.blic.be.

[3] RMA, www.rma.org.

[4] RMA, www.rma.org.

[5] Pehlken, A., Scrap Tire Recycling in Canada, Report for Natural Resources Canada, Canada, August 2005.

[6] ETRA, www.etra.eu.com.

[7] ICF Consulting, Determination of the Impact of Waste Management Activities on Greenhouse Gas Emissions: 2005 Update, Draft report, Environment Canada \& Natural Resources Canada, Canada, 2005.

[8] Atech Group, A National Approach to Waste Tyres, Commonwealth Department of Environment, ISBN 064254749 1, Australia, June 2001.

[9] Reschner, K., Scrap tyre recycling - Market overview and outlook; Waste Management World; July-August 2003.

[10] Global temperature change and its uncertainties since 1861, by Folland, C.K et al., Geophys Res. Lett, 28, pp 2621- 2624 (2001).

[11] Warming of the world ocean, by Levitus, S. et al., Science, 287, pp.2225 2229, (2000). 